\title{
SISTEM PANAS BUMI DAERAH CANDI UMBUL-TELOMOYO BERDASARKAN KAJIAN GEOLOGI DAN GEOKIMIA
}

\author{
Oleh: \\ Dudi Hermawan, Sri Widodo, Eddy Mulyadi \\ Pusat Sumber Daya Geologi \\ Jl. Soekarno Hatta No. 444 Bandung
}

\begin{abstract}
SARI
Sistem panas bumi daerah Candi Umbul-Telomoyo, Jawa Tengah merupakan salah satu lapangan panas bumi di Indonesia yang terbentuk pada lingkungan magma basaltik. Fluida panas satu fasa bertemperatur tinggi terbentuk pada zona resevoir yang memiliki permeabilitas tinggi sebagai fasa cair. Fluida ini dapat tersimpan dengan baik di reservoir dikarenakan ditutupi lapisan penudung berupa batuan ubahan yang bersifat kedap air. Zona upflow dari sistem panas bumi Telomoyo terbentuk di dalam kaldera komplek Telomoyo, sedangkan zona outflow terbentuk di daerah sekitar manifestasi Candi Dukuh, Candi Umbul dan Pakis Dadu. Karakteristik sistem panas bumi daerah Candi Umbul-Telomoyo menunjukkan bahwa daerah ini potensial untuk dikembangkan.
\end{abstract}

Kata kunci : sistem panas bumi, sumber panas, reservoir, batuan penudung, fluida panas.

\section{ABSTRACT}

Candi Umbul-Telomoyo geothermal system is one of the Indonesia geothermal field that formed in basaltic magma environment. Single phase high temperature thermal fluids formed in the resevoir zone that has a high permeability as liquid phase. This fluid can be stored in the reservoir due to the covering of alteration as cap rocks. Upflow zones of Telomoyo geothermal system formed within the caldera of Telomoyo complex, while its outflow zone formed at around of the manifestations of Candi Dukuh, Candi Umbul, and Pakis Dadu. Characteristics of the Candi Umbul-Telomoyo geothermal system indicate that this area is potentially developed.

Keywords : geothermal system, heat sources, reservoir, cap rock, hot fluids.

\section{PENDAHULUAN}

Keberadaan sistem panas bumi pada umumnya berkaitan dengan magmatisme yang terbentuk di suatu daerah. Posisi geografis Indonesia yang terletak pada jalur gunung api (ring of fire) merupakan wilayah yang memiliki suatu potensi panas bumi.

Sistem panas bumi adalah energi yang tersimpan dalam bentuk air panas atau uap pada kondisi geologi tertentu pada kedalaman beberapa kilometer di dalam kerak bumi (Rybach, 1981). Sistem panas bumi ini merupakan gabungan dari beberapa unsur, yaitu : sumber panas (heat sources), reservoir, batuan penudung (cap rock), dan fluida panas.

Sistem panasbumi terbentuk sebagai hasil perpindahan panas dari sumber panas di sekelilingnya yang terjadi secara konduksi dan secara konveksi. Perpindahan panas secara konduksi terjadi melalui batuan, sedangkan perpindahan panas secara konveksi terjadi karena adanya kontak antara air dengan suatu sumber panas.

Kontak antara air meteorik dengan panas di kedalaman membentuk fluida panas di reservoir. Reservoir merupakan batuan yang memiliki permeabilitas tinggi sehingga bisa menjadi tempat terakumulasinya fluida. Fluida panas ini tidak keluar atau bocor ke permukaan dikarenakan ditutupi oleh batuan penudung yang merupakan batuan yang kedap air (impermeable). Adanya struktur geologi berupa patahan yang memotong reservoir, menyebabkan fluida panas ini dapat keluar ke permukaan berupa manifestasi panas 
bumi (misalnya air panas).

Suatu lapangan panas bumi mempunyai karakteristik sistem panas bumi dengan ciri khas tersendiri. Daerah panas bumi Candi Umbul-Telomoyo merupakan salah satu lapangan panas bumi di Indonesia yang terbentuk pada suatu komplek gunungapi Kuarter yaitu komplek Telomoyo. Penelitian panas bumi lebih detail di daerah ini sangat diperlukan untuk mengetahui pembentukan sistem panas bumi, daerah prospek dan potensi energi panas bumi.

Penelitian panas bumi di daerah ini telah dilakukan oleh Pertamina dari tahun 19881993 berupa pengumpulan data geologi, geokimia, dan geofisika hingga pengeboran landaian suhu. Sedangkan pada tahun 2010, Pusat Sumber Daya Geologi, Badan Geologi juga telah melakukan Survei Terpadu Geologi dan Geokimia serta Survei Magnetotellurik di daerah ini. Hasil dari penelitian sebelumnya ini menunjukkan bahwa daerah panas bumi Candi UmbulTelomoyo ini memiliki karakteristik geosains yang sangat menarik. Namun hasil penelitian sebelumnya ini belum membahas lebih detail mengenai unsur pembentukan sistem panas-bumi, sehingga pada makalah ini akan dibahas berdasarkan data geosains daerah panas bumi Candi Umbul-Telomoyo yang meliputi data geologi dan geokimia. Tujuannya adalah untuk lebih memahami lagi tentang karakteristik dan proses pembentukan sistem panas bumi daerah ini sehingga diharapkan dapat dijadikan salah satu acuan dalam proses pengembangan selanjutnya.

\section{METODOLOGI}

Metode yang digunakan dalam makalah ini terdiri dari studi literatur dan kajian data sekunder berupa analisis data geologi dan data geokimia.

Dalam studi literatur dikaji teori-teori dasar dari pembentukan sistem panas bumi untuk mempelajari/mengumpulkan data yang relevan sebagai pembanding penulisan makalah ini. Studi literatur menghasilkan kerangka berpikir dan efisiensi pembahasan yang lebih terarah.

Analisis data geologi adalah mengkaji data geologi yang ada seperti stratigrafi, pola struktur geologi, batuan ubahan, dengan tujuan untuk mengetahui dan memahami tatanan geologi yang membentuk daerah kajian.

Analisis data geokimia berupa kajian tentang karakteristik fluida panas bumi yang diperoleh dari jenis manifestasi dan konsentrasi senyawa kimia terlarut yang terabsorpsi dalam fluida.

Dari analisis-analisis tersebut, maka dikompilasikan dalam suatu model tentatif sistem panas bumi yang bisa menggambarkan proses pembentukan sistem panas bumi di daerah Candi UmbulTelomoyo.

Makalah ini bersumber dari laporan Pertamina (1988-1993) berupa pengumpulan data geologi, geokimia, dan geofisika hingga pengeboran landaian suhu serta hasil survei terpadu panas bumi, PSDG, 2010 dan makalah "Delineasi Daerah Prospek Panas Bumi Berdasarkan Analisis Kelurusan Citra Landsat di Candi UmbulTelomoyo", Provinsi Jawa Tengah (Dudi Hermawan, Yuanno Rezky, 2011), dengan melakukan pendekatan geosains dari teori kepanasbumian yang telah ada.

\section{GEOLOGI DAN GEOKIMIA}

Daerah panas bumi Candi UmbulTelomoyo terletak pada zona Pegunungan Serayu Utara, dengan batuan tertua adalah batuan sedimen berumur Miosen Tengah dengan mekanisme pengendapan turbidit dalam lingkungan neritik. Pada Kala Pliosen Atas terjadi proses pengangkatan yang diikuti oleh erupsi efusif Ungaran Tua pada Kala Plistosen Awal yang menghasilkan satuan lava Ungaran-1. Selain itu di sebelah tenggara Ungaran terjadi aktivitas vulkanik Telomoyo-1 yang menghasilkan endapan lava dan piroklastik. Letusan besar Telomoyo-1 menyebabkan terjadinya runtuhan (collapse) dan menghasilkan struktur kaldera yang diikuti oleh munculnya kembali aktivitas vulkanik post-kaldera Telomoyo-2 yang menghasilkan endapan lava dan piroklastik. Aktivitas vulkanik terus berlanjut hingga membentuk kerucut Telomoyo sekarang yang berkomposisi andesit-basaltik dan kerucut Andong. Fase akhir aktivitas vulkanik Telomoyo dicerminkan oleh pembentukan kerucut skoria (scoria cone). Saat itu di sebelah utara (Gunung Ungaran) dan sebelah selatan (Gunung Merbabu) juga terjadi aktivitas vukanik yang menghasilkan endapan lava dan piroklastik. Endapan lahar dan aluvium 
terbentuk di sepanjang pedataran dan sungai-sungai besar (Gambar 1). Struktur geologi yang berkembang terdiri dari struktur kaldera dan sesar-sesar normal berarah baratdaya-timurlaut yang terbentuk akibat aktivitas Gunung Telomoyo, serta sesarsesar mendatar berarah relatif utara-selatan dan baratlaut-tenggara yang merupakan struktur regional dan sebagian sudah ditutupi oleh produk batuan yang lebih muda (PSDG, 2010).

Daerah yang diperkirakan memiliki kerapatan tinggi struktur geologi dan diperkirakan mempunyai zona permeabilitas yang tinggi terletak di bagian utara kerucut muda Telomoyo yaitu dari lereng baratlaut kerucut muda Telomoyo memanjang ke utara-timurlaut sampai daerah Keningar dan Candi Dukuh (Dudi Hermawan dan Yuanno Rezky, 2011).

Manifestasi panas bumi di daerah Candi Umbul-Telomoyo terdiri dari mata air panas yang tersebar di tiga lokasi yaitu mata air panas Candi Dukuh dengan temperatur berkisar antara $35-36^{\circ} \mathrm{C}$, serta mata air panas Candi Umbul dan Pakis Dadu dengan temperatur berkisar antara $35-36^{\circ} \mathrm{C}$.
Selain manifestasi berupa mata air panas, di daerah ini ditemukan juga batuan ubahan yang tersebar cukup luas di tiga lokasi yaitu di daerah Sepakung, Keningar dan Kendal Duwur. Batuan ubahan ini terdiri dari kelompok alunit-kaolinit dan mineral lempung monmorilonit serta haloisit sehingga dapat dikelompokkan ke dalam tipe ubahan argilik-argilik lanjut.

Fluida panas merupakan air tipe klorida-bikarbonat pada zona immature water yang memberikan gambaran bahwa kondisi air panas kemungkinan berasal langsung dari kedalaman, tetapi selama dalam pencapaian ke permukaan kemungkinan telah mengalami kontaminasi atau pengenceran oleh air permukaan yang cukup dominan.

Berdasarkan data pengeboran landaian suhu yang dilakukan Pertamina, dapat diketahui bahwa batuan penyusun sumur tersebut sampai kedalaman $502 \mathrm{~m}$ terdiri dari breksi tufa, breksi andesit, andesit dan tufa yang telah mengalami ubahan hidrotermal dengan intensitas ubahan 30$65 \%$ jenis argilitisasi sampai silisifikasi (Tabel 1). Nilai landaian suhu pada pemboran di lokasi ini sekitar $10^{\circ} \mathrm{C} / 100 \mathrm{~m}$.

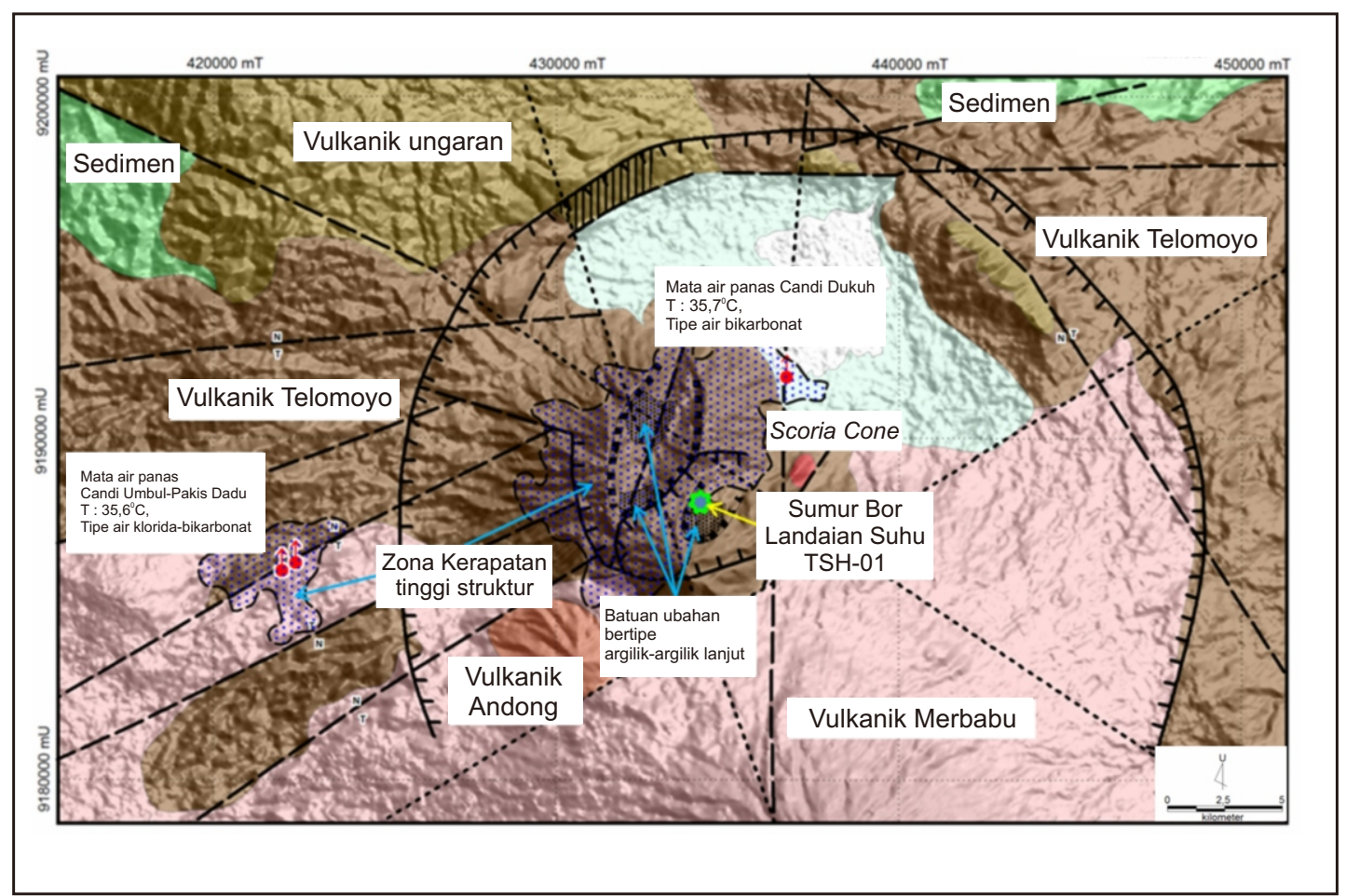

Gambar 1. Peta Geologi Daerah Panas Bumi Candi Umbul-Telomoyo (Modifikasi dari Peta Geologi Tim Survei Terpadu Panas Bumi, PSDG, 2010) 
Tabel 1.

Komposit log hasil pemboran landaian suhu sumur TSH-01 (Pertamina, 1993)

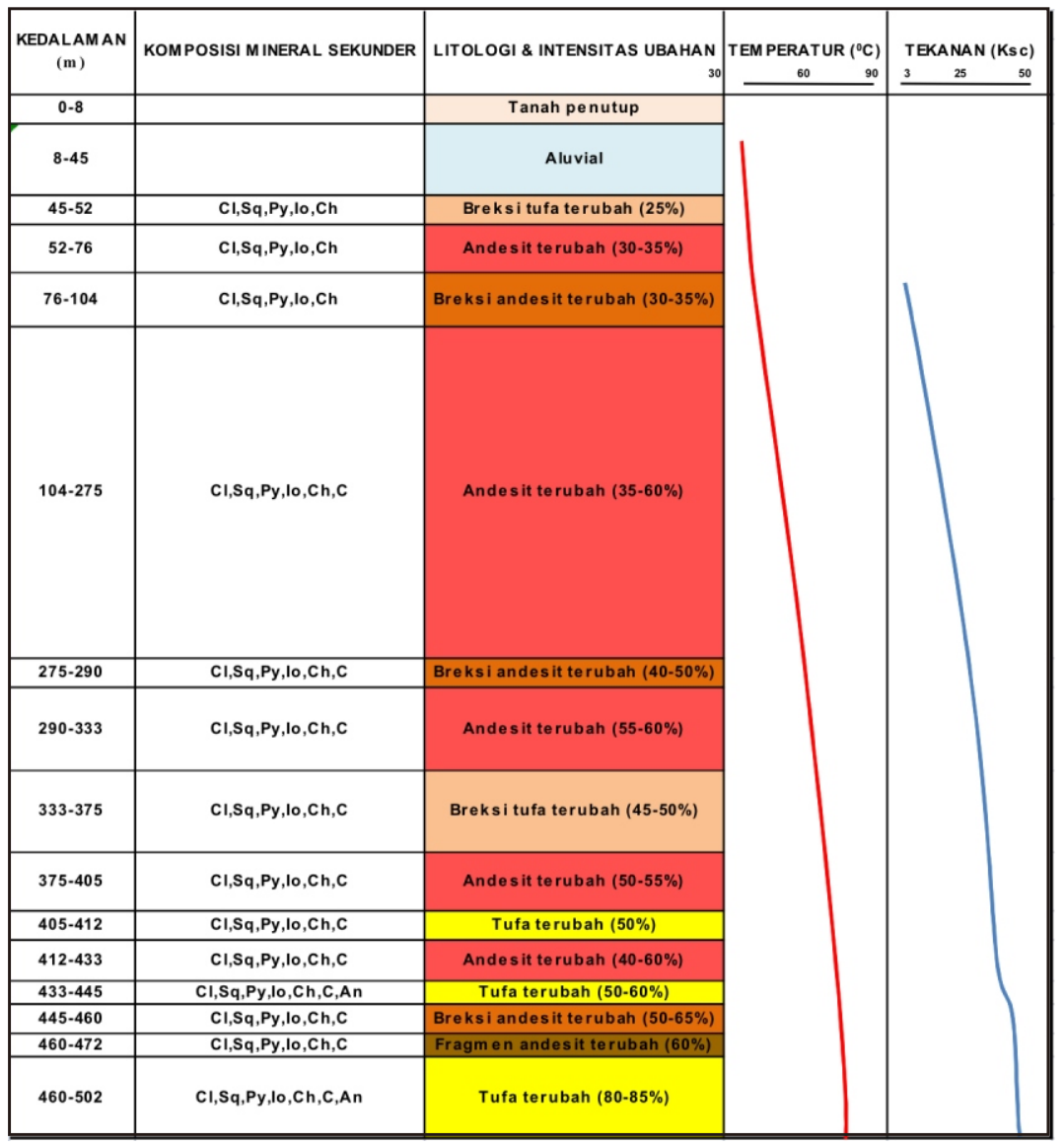

\section{PEMBAHASAN}

Sumber panas yang membentuk sistem panas bumi Candi Umbul Telomoyo adalah sisa panas dari magma pada lingkungan magma basaltik yang berasosiasi dengan aktivitas vulkanik termuda komplek Telomoyo. Magma basaltik memiliki viskositas yang rendah, sehingga sifat fisiknya relatif lebih encer dibandingkan dengan magma silisik, akan tetapi densitasnya lebih tinggi, yang diakibatkan tingginya konsentrasi mineral mafik (besi dan magnesium). Karena sifatnya yang lebih cair, magma ini cenderung mampu bergerak sampai ke permukaan melalui rekahanrekahan membentuk kerucut muda Telomoyo. Sedangkan magma yang tidak berhasil menembus sampai permukaan terperangkap di kedalaman yang dangkal membentuk kantong-kantong magma. Akibat kontak dengan batuan sekitar, kantong magma kehilangan panas secara konduktif dan panas yang dilepas berinteraksi dengan air meteorik membentuk sistem panas bumi.

Fluida panas bumi di daerah ini berasal dari air permukaan/meteorik yang masuk ke bawah permukaan membentuk sistem kantong fluida/reservoir melalui rekahan maupun ruang antar butiran. Interpolasi data pengukuran landaian suhu menunjukkan bahwa temperatur reservoir pada kedalaman $2.000 \mathrm{~m}$ sekitar $230^{\circ} \mathrm{C}$ yang termasuk ke dalam kategori entalpi tinggi.

Reservoir daerah ini merupakan zona yang tersusun oleh batuan yang memiliki sifat sarang. Permeabilitas dihasilkan oleh karakteristik stratigrafi (misal porositas intergranular pada lapilli, atau lapisan bongkah-bongkah lava) dan unsur struktur (misalnya sesar, kekar, dan rekahan). Geometri reservoir hidrotermal di daerah vulkanik merupakan hasil interaksi yang kompleks dari proses vulkano-tektonik aktif antara lain stratigrafi yang lebih tua dan struktur geologi. Resevoir yang membentuk sistem panas bumi daerah Candi UmbulTelomoyo terletak pada lingkungan batuan 
vulkanik dan sedimen yang memiliki permeabilitas tinggi. Pada umumnya batuan vulkanik dan sedimen memiliki permeabilitas primer yang kecil. Akan tetapi tingginya intensitas struktur geologi yang berkembang mengakibatkan terbentuknya permeabilitas sekunder yang tinggi sehingga dapat menyimpan fluida panas bumi yang potensial.

Batuan penudung di daerah Candi Umbul-Telomoyo terdapat pada batuan vulkanik yang telah mengalami ubahan di dalam kaldera letusan Telomoyo yang merupakan bukti adanya interaksi fluida panas bumi dengan batuan yang dilewatinya melalui jalur-jalur rekahan. Batuan penudung ini bersifat kedap atau memiliki permeabilitas rendah yang berfungsi sebagai penutup reservoir untuk mencegah keluar atau bocornya fluida panas bumi dari reservoir.

Dengan tidak ditemukannya manifestasi panas bumi seperti fumarol, dan temperatur reservoir sekitar $230^{\circ} \mathrm{C}$ pada kedalaman yang cukup dalam (2.000 m), maka reservoir di daerah ini diduga merupakan reservoir satu fasa yaitu fasa air.

Berdasarkan pemunculan manifestasi permukaan berupa batuan ubahan di dalam kaldera komplek Telomoyo (daerah Sepakung, Keningar, dan Kendal Duwur) dan jenis fluida yang mempengaruhi proses ubahan, maka diperkirakan bahwa daerah ini merupakan zona upflow. Sedangkan daerah Candi Dukuh, Candi Umbul dan Pakis Dadu tempat munculnya mata air panas sebagai zona outflow.

\section{KESIMPULAN}

Hasil kajian ini menunjukkan bahwa sistem panas bumi Candi Umbul-Telomoyo terbentuk pada lingkungan magma basaltik yang berasosiasi dengan aktivitas vulkanik terakhir Komplek Telomoyo. Fluida panas bertemperatur tinggi terakumulasi di reservoir membentuk sistem satu fasa yaitu fasa air. Lapisan reservoir ini ditutupi oleh lapisan penudung berupa batuan ubahan yang kedap air yang juga tersingkap luas di permukaan.

Zona upflow terbentuk di dalam kaldera komplek Telomoyo, sedangkan daerah sekitar menifestasi Candi Dukuh, Candi Umbul dan Pakis Dadu merupakan zona outflow dari sistem panas bumi Candi Umbul-Telomoyo.

Dengan karakteristik sistem panas bumi seperti ini, daerah panas bumi Candi UmbulTelomoyo potensial untuk dikembangkan, dengan mempertimbangkan peluang dan hambatan yang mungkin akan dihadapi (misalnya teknologi eksplorasi yang akan digunakan).

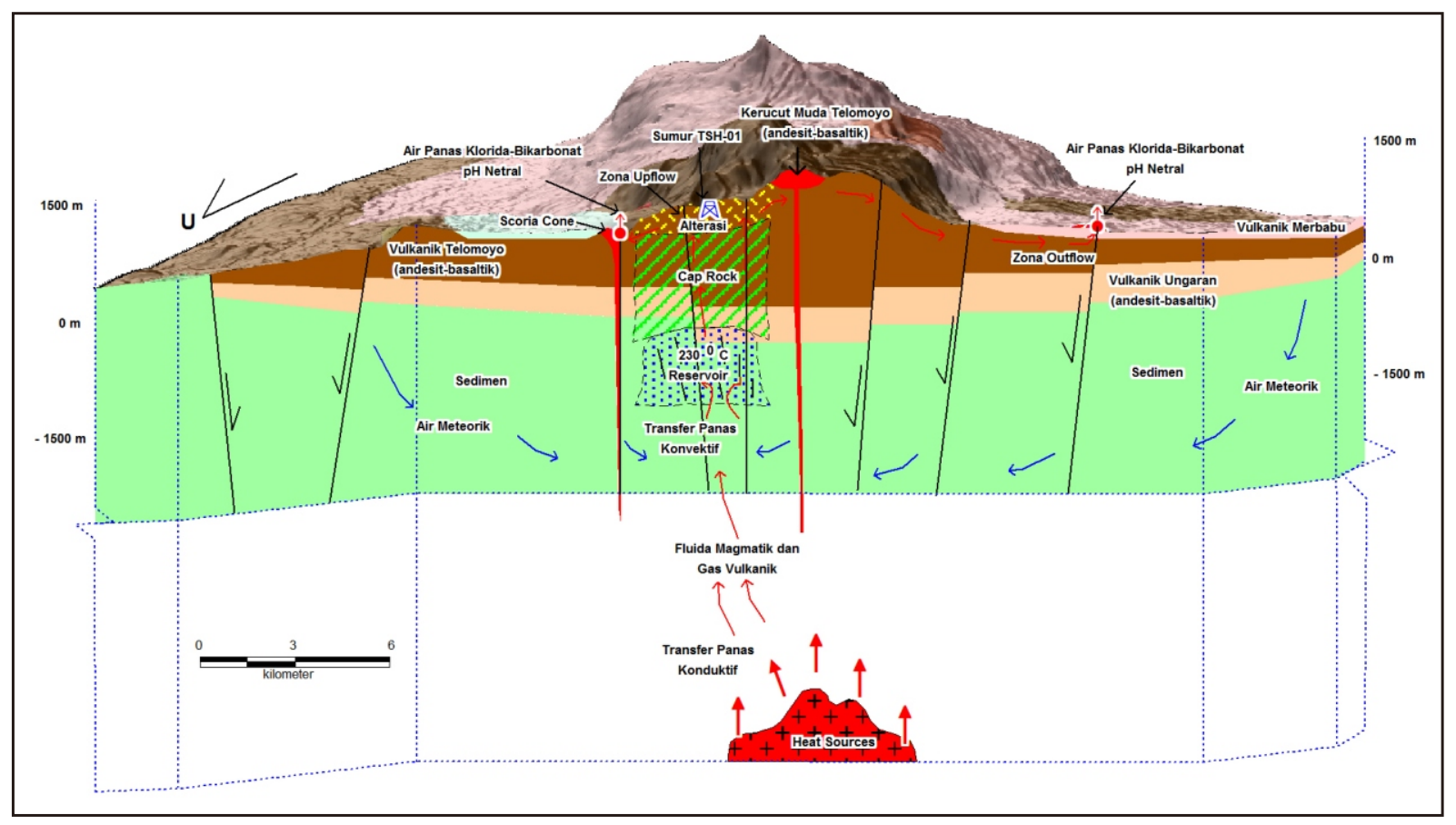

Gambar 2. Model tentatif sistem panas bumi Candi Umbul-Telomoyo 


\section{UCAPAN TERIMAKASIH}

Ucapan terima kasih kami ucapkan kepada rekan-rekan yang telah memberikan masukan, dan tim editor yang telah mengoreksi dan memberikan saran dalam penyusunan makalah ini. Serta kepada dewan redaksi yang telah memberikan kesempatan makalah ini sehingga dapat diterbitkan.

\section{DAFTAR PUSTAKA}

Anonim, 2010. Laporan Survei Terpadu Geologi dan Geokimia Daerah Panas Bumi Candi Umbul-Telomoyo, Provinsi Jawa Tengah, Pusat Sumber Daya Geologi, Bandung (unpublished report)

Anonim, 1993, Laporan Akhir Pengumpulan Data Geologi, Geokimia, dan Geofisika serta Pengukuran Landaian Suhu di dalam Sumur Dangkal di daerah Telomoyo-Jawa Tengah. Pertamina, Jakarta

Anonim, 1989, Geologi dan Alterasi Batuan Daerah Gunung Telomoyo, Jawa Tengah. Pertamina, Jakarta

Anonim, 1988, Laporan Survey $\mathrm{Hg}$ dan $\mathrm{CO}_{2}$ daerah Gunung Telomoyo, Jawa Tengah. Pertamina, Jakarta

Hayashi, M., 1973. Hydrothermal alteration in the Otake geothermal area, Kyushu. J. Japan Geotherm. Energy Assoc.

Hermawan, D. dan Rezky, Y., 2011, Delineasi Daerah Prospek Panas Bumi Berdasarkan Analisis Kelurusan Citra Landsat di Candi Umbul-Telomoyo, Provinsi Jawa Tengah, Bul. Sumber Daya Geologi, Pusat Sumber Daya Geologi, Bandung

Robert E.Thaden, dkk, 1975, Geologi Lembar Magelang dan Semarang, Pusat Penelitian dan Pengembangan Geologi.

Rybach, L, 1981, Geothermal systems: conductive heat flow, geothermal anomalies.In:

Rybach, L,and Muffler, L.J.P, (eds) Geothermal systems. Wiley, New York, 3-36

Soengkono, S., Te Kopia geothermal system (New Zealand) - the relationship between its structure and extent, Geothermics 28 (1999a), page 767-784.

Soengkono, S., Analysis of Digital Topographic Data for Exploration and Assessment of Geothermal System, Proceeding 21st New Zealand Geothermal Workshop (1999b).

Suryantini and Hendro Wibowo, Application of Fault and Fracture Density (FFD) Method for Geothermal Exploration in Non-Volcanic Geothermal System; a Case Study in Sulawesi-Indonesia.Proceedings World Geothermal Congress 2010. Bali, Indonesia. 